\title{
The socio-economic importance of Calabar Carnival on the economic development of Cross River State
}

\author{
Felicia Ebeyin Odere ${ }^{\star}$ and Felix Ojong \\ Department of Sociology, University of Calabar, Cross River State, Nigeria. \\ *Corresponding author. Email: oderefelicia@gmail.com
}

Copyright (c) 2021 Odere and Ojong. This article remains permanently open access under the terms of the Creative Commons Attribution License 4.0, which permits unrestricted use, distribution, and reproduction in any medium, provided the original work is properly cited.

Received 10th November, 2021; Accepted 7th December, 2021

\begin{abstract}
The study investigates the socio-economic importance of the Calabar Carnival on the economic development of Cross River State, Nigeria. To establish the relationship between the festival and the development of Cross Rivers State, hypotheses were formulated based on the identified major independent variables namely: employment creation, income generation, and infrastructural development while the dependent variable is the Calabar Carnival Festival. Literatures related to the major variables of the study were reviewed. To generate data for hypotheses testing, questionnaire was used; survey research design was adopted for study while utilizing the convenience sampling technique to select the respondents (300) for study. The generated data were statistically tested at a 0.05 level of significance using Pearson Product Moment Correlation Coefficient analysis. The analysis showed that the Calabar carnival has significant relationship with job creation, income generation, and infrastructural development in Cross River State. Based on the result of the findings, the study recommended the need for tourism industry be fortified with security and as well be privatized. Also, the study recommends that youth development should be a cardinal point in the carnival as a promotional strategy in other to accelerate the state's socio-economic development.
\end{abstract}

Keywords: Calabar, carnival, Cross River State, festival, socio-economic.

\section{INTRODUCTION}

\section{Background to the study}

The festival which heralds the carnival proper is unarguably the major and best multi-purpose relaxation and entertainment event in Sub-Saharan Africa tagged "Africa's biggest street party". It was created as part of the vision to making the Cross River State number one tourist destination in Nigeria and the world at large. This vision was the brainchild of the then Governor, Mr. Donald Duke whose mission was to make Calabar the tourism hub of Nigeria and West Africa at large (Ulom, 2016).

It started in 2004 with the first ever edition. The event serves as a great platform where individuals and business entities show case their wares for patronage. According to Isine (2015), the carnival aimed to include more aspects of local heritage and culture and at the same time strengthen the capacity of the locals to participate in an economically beneficial way. Esekong and Ibok (2012) reported more than $50 \%$ increase in the number of visitors to Cross Rivers every December since the start of the carnival therefore showing that as far as tourism, carnival and hospitality business is concerned, Cross River State has recorded remarkable successes as the state is globally recognised as tourist destination.

The event which starts on the last day in the eleventh month of every year with a tree lighting exercise at the Millennium Park in the state capital ends with a special thanksgiving service on the first day of another year. The church activity marks the end of Christmas Festival for that year. It takes a total of thirty-two days of exciting events, colourful activities and an unprecedented yearly participation of over a million people from all over the world (CRTB, 2013).

The event is organised in such a way that each day has its unique programme. The show usually spills over the Millennium Park around Eleven-Eleven roundabout. This 
Integ. J. Arts and Human.

area presents lots of fun to fun-lovers and business opportunities to hawkers and street traders. Other forms of business activities such as roadside shops, drinking bars, barbecue, casino and different kinds of musical entertainment make this area lively for fun-seekers. Others include the high vibrating steel orchestra, comedy galore, family funfair, Santa Claus grotto, raffle draws, lottery, firework, jazz night, Governor's tree lighting ceremony (Achonwa, 2007).

Tourism industry in any country is a productive sector in the sense that it has the capacity for wealth creation, employment creation and enhancing the well-being of people by sustaining their source of livelihood. The sister industry- the travel and tours poses great potentials that helps promote and sustain tourism activities in given economy. Tourism creates enviable possibility for exportation, investment in various sectors of the economy and boosts job creation (WTO, 2016).

Globally, Africa continent is recognised as the largest tourism destination. Internationally, Nigeria is rated among one of the countries that is widely visited for tourism activities in Sub-Saharan Africa. The business potentials offered by tourism if effectively harnessed has the capacity to drive the economy of a state to the next level (lain et al., 2009). Indeed, the Calabar carnival has the potentials of working for the social and economic good of all Nigerians if the fabrics of the costumes used by the various bands are sourced locally.

The increasing rate of global patronage of tourism in third world countries has made Africa top in the chart of tourist destination in the world. Records reveal that more than 7.5 per cent accounting for 360 million tourists visited various tourist sites in Africa in 1998 (Odunsawo, 2009). In 2004, WTO rated Nigeria as one of the widely visited country in Sub-Saharan Africa with tourism potentials. Statistics show that if the tourism potentials of the state are enhanced, it would be of immense benefit to the state economy and its agricultural sector (Ajake, 2005).

Socio-economic advancement is the goal of every responsible government. This implies that socio-economic enhancement has its focus on discovering the desires of the people within a community which centres on their social and economic needs as well as establish opportunities that will practically solve the problem of the people both in short and long term (Allen, 2002).

In recent times, the two major forms of tourism activities are carnivals and cultural events. These events are widely practiced in all parts of the state with the carnival fiesta organised once every year in the state. Through this medium, the state has been able to boost her internally generated revenue with over $35 \%$ for optimum service delivery (Ukwayi et al., 2012). It has been noticed that Calabar Carnival is a prime example which has become increasingly popular among tourists and injecting extra revenue into the state between the Christmas and New Year. The period of this festival and other events encourages numerous visitors to attend and often attracting new visitors that would otherwise not experience Cross River State (Felsenstein and Fleischer, 2003).

According to Esu et al. (2011), tourism, particularly the annual Calabar Carnival is one of the critical sectors in the state that generates close to 40 per cent of the state revenue. The event is a yearly exercise that has significantly contributed to the social and economic enhancement of the state.

The annual event attracts people from all walks of life especially youths who seize the opportunity to have fun. Indeed, the goals of the organiser of this yearly event is to create an event that will be of international standard as well as meet the yearnings of fun seekers who troop into the state to see the annual rituals. Achonwa (2007) said that the yearly event has been designed to be the major driving force of the state economy. He observed that the tourism potentials of the state is so great that it has the capacity of weaning the state of absolute dependence on federal allocation on monthly basis as well as provide a feasible means of generating funds for those involved in managing the tourism sector. The annual event has the potentials to achieve more than this.

The 2013 carnival was the ninth edition. According to the CRTB (2013), more than one million spectators witnessed the annual event in the state. Nigerians accounted for about 85.9 per cent while foreigners accounted for the rest 14.1 per cent. Record shows that 46.6 per cent resides within the state, 45.7 per cent were fun lovers from neighbouring states while 7.7 per cent were day-trippers Esu (2008).

The annual festival is characterized with activities such as; colourful masquerade parades, traditional songs, entertaining band procession among others. During the preparation for this colourful event, carnival queen is selected through a special process by the organisers of the event. All young ladies irrespective of their state of origin are allowed to participate in the exercise. The high point of the annual festival is the street party. This moment is usually welcome with great excitement and jubilation among the young and old in the state and viewers across the globe. It involves a long-distance trek of various carnival bands, dressed in lovely attires and dancing as well as entertaining spectators in designated carnival route. The former governor of the state in 2007 pioneered the children carnival, five carnival bands was introduced and children were selected from public and private schools, orphanages and young tourists to belong to any band of their choice. More than five thousand children took part in the children carnival with about twenty thousand spectators in attendance (Esekong and lbok, 2012).

\section{Statement of the research problem}

The socio-economic importance of Calabar carnival has posed an enormous concern to people and stakeholders in the area of tourism. Throughout history, human beings 
have travelled for acquisition of resources but the idea of traveling for leisure or exploration also emerged in recent times. Tourism in today's world however, is believed to encompass programs, services and industries that deliver a travel experience, which includes movement of tourists, lodging, entertainment, business and other tourist services delivered to individuals or corporate entity travelling away from home.

The global trend is that every nation across the world is making frantic effort to attract more visitors to their country to explore her tourism potentials. The decrease (promo) in cost of air travels, and the introduction of ICT technology like the internet, online booking etc., have aided the promotion of tourism activities irrespective of where you find yourself. Nonetheless, both political and business leaders have indeed succeeded in universally recognising the economic advantages that tourism offer. While the economic benefits of tourism is juicy and have long been discovered, greater attention is being paid to the social impact, which can be both positive and negative depending on the planning and management.

In recent times, the rate of visitors in Cross River State as a result of the carnival is quite overwhelming in spite of the multiplier effect accrued from the carnival, the people of the area, yet still remain poor, besides emerging businesses seem to be suffering from seasonal fluctuation which affects both employment and the revenue base of the state. It is for this reason that this study was conducted to investigate the socio-economic importance of Calabar Carnival for the socio-economic enhancement of the state. Based on the above, some problem areas were identified (Esekong and lbok 2012);

1. The problem of not fully engaging the people in the planning process.

2. Poor road network leading to the state (single entry/exit point).

3. Seasonal fluctuations in businesses at off-peak season.

4. Security concerns due to the high rate of crime/criminality that accompanies the carnivals etc.

It is hoped that this study answers questions about how Calabar festival relate to employment creation, income generation and infrastructural development in the study area.

\section{Aims and objectives of the study}

These aims are derivatives from the statement of the study, and sought to contribute to existing knowledge and also broaden the horizon for solving issues as they relate to tourism and other related industries. However, the primary objective of this research aside fulfilling an academic requirement is;

1. To examine whether Calabar Carnival has any relationship with employment creation in Cross River State.

2. To establish the relationship between Calabar Carnival and income generation in Cross River State.

3. To investigate the relationship between Calabar Carnival and infrastructure development in Cross River State.

4. Finally, to make appropriate recommendations where necessary to improve on any lacuna that exists in the study.

\section{Research questions}

The following research questions were put forth as a guide for this study;

1. Is there any significant correlate between job creation and Calabar carnival festival?

2. Does Calabar carnival significantly relate to income generation in Cross River State?

3. Is there any significant correlate between Calabar carnival and the provision of infrastructure in Cross River State?

\section{Research hypothesis}

The following hypotheses were put forth in order to ascertain relationship does exist between key variables;

$\mathrm{H}_{01}$ : There is no significant relationship between Calabar Carnival and job creation in Cross River State.

$\mathbf{H}_{02}$ : Calabar Carnival does not significantly relate to income generation in Cross River State.

$\mathbf{H}_{03}$ : Calabar Carnival does not significantly relate to infrastructure development in Cross River State.

\section{Significance of the study}

This research will be of enormous advantage to all Cross Riverians and Nigerians as a nation in her quest to properly and professionally develop, package and market the tourism potential of the country. This when done properly through utilising the VALs tools which means "value, attitude and lifestyle" as it relates to the state will greatly improve the overall perception of all people of the state, as well as the visitors, thereby serving as a window to marketing the state tourism products or potentials to the international market.

This study will therefore significantly enhance the reviews of various policies and appropriately put in place guidelines for sustainable tourism development and the management of tourism activities such as the Calabar Carnival. These guidelines will be a benchmark for policy makers/stakeholders, private/corporate entities with responsibilities bordering on the carnival and other 
tourism-related activities in the state and national levels.

Finally, the result of this study is expected to aid the State Government and policy makers to evaluate the progress made so far as well as come up with ideas that will help in repositioning the annual event. The finding of the study is required to guide future planning and funding of the Calabar Carnival in the nearest future.

\section{Scope of the study}

The study assesses the socio-economic implication of Calabar Carnival in Cross River State, Nigeria. This study was limited to Calabar which is the capital of Cross River State. The major concentration was on employment creation, income generation and infrastructure development. Thus, the study was restricted to only the variables of the hypotheses.

\section{RESEARCH METHODOLOGY}

\section{Study area}

The study area is Calabar in Cross River State. The study site is the Calabar Carnival in the state. It operates in three senatorial districts namely Northern, Central and Southern senatorial districts. The state exists in a tropical rainforest belt of the country. It lies between latitude $4^{\circ} 28^{\prime}$ and $6^{\circ} 55^{\prime}$ North of the equator and longitude $7^{\circ} 50^{\prime}$ and $9^{\circ} 28^{\prime}$ East of the Greenwich meridian. It also shares the common boundaries with the Republic of Cameroon in the East, Benue State in the North, Ebonyi and Abia States in the West, Akwa Ibom State in the South-East and Atlantic Ocean in the south. It has a total landmass of 22,342.185 $\mathrm{km}^{2}$, with a population of $2,888,966$ people (BasseyAkamune and llomuanya, 2021).

Cross River State has Calabar as its capital. It is characterized by different ethnic groups as well as natural inheritance which have the capacity of improving tourism industry in the state. Indigenes of Cross River State are noted for their warmth and hospitality. The people of Cross River State are predominantly Christians with few Muslims and traditional worshippers. The three major dialects dominantly used during interaction in the state are Efik, Bekwarra, Ejagham. Nevertheless, all the language groups have a common linguistic group that is traceable to a common ancestry (Falola et al., 2020).

The capital city of Calabar has a lot of bars, restaurants, hotels, motels, etc. and hosts the annual event that attracts people from far and near to the state for merriment and entertainment. The carnival festival is a collection of colourful events. The cultural event is held in two days: 26th (children carnival) and 27th (the main carnival) December.

\section{Research design}

The study adopted a survey research design by Kerlinger
(1986). Survey research design is that which is directed towards determining the nature of a situation as it exists at the time of investigation whereas the researcher has no direct control of independent variables. Survey design enables the researcher to use part of a population for the study and then generalize the result to the whole population. In the light of the above, the researcher did not manipulate any of the variables but surveyed what is already in existence by descriptive means through the use of questionnaires as a method of data collection.

\section{Population of the study}

Fun-seekers to this annual event constitute the population of the study. They are aged between five and above who participated in any form of the activities going on in the carnival route. The carnival routes are Millennium Park, Mary Slessor, Marian Road, Murtala Muhammed highway and finally the Calabar Stadium. The audience (funseekers) in the definition of the researcher are those found along carnival route watching the performance of carnival bands or transacting one form of business or the other. Statistics from the state tourism Bureau revealed that there are two million visitors found watching the carnival floats along the routes.

The day-trippers and resident spectators consist the targeted population of the study. The sample of this study was selected from this targeted population.

\section{Sampling technique}

The study adopted convenience sampling procedure. The method of sampling enables the researcher to get a gross estimate without incurring costs or time required to select a random sample. On the carnival days (December 26 and 27), respondents found on the carnival route were given the questionnaire to fill and was returned immediately afterward. In all, 320 questionnaire were distributed while only 300 were properly filled. It was based on the correctly field questionnaire that the analysis of the study was done.

\section{Sample size}

Three hundred and twenty (320) were distributed randomly, three hundred (300) of the respondents correctly responded to the questions asked. The sample population consists of people between 5 to 55 years old and resident spectators who took part in the annual event in Calabar, Cross River State, Nigeria.

\section{Sources of data collection}

The research adopted the primary source of data in accomplishing this study. The primary source of data used 
here is the questionnaire, and also support personal interview and focus group discussion.

\section{Research instrument}

Questionnaire was the major instrument of data collection. It was structured into three segments: A, B, C. Section "A" focused on the respondents' personal information such as sex, age, marital status, occupation, etc. Section "B" deals with the questionnaire items on the variables of the study such as job creation, income generation and infrastructural development, while sections " $\mathrm{C}$ " focused on the questionnaire item on the dependent variable item which would be measured using "4-point Likert type scale such as "SA" for Strongly Agreed, "A" for agreed, "D" for Disagreed and "SD" for Strongly Disagree".

\section{Validity and reliability}

The instruments validity was a measurement of how they are capable of eliciting the information needed for the study. The content validity was employed. The research carefully designed the instrument to cover the entire issues involved in the study. The test-retest reliability was used to ensure the reliability of the instrument. At least 50 questionnaires were distributed to the population not involved in the study but in the same study area. These were analysed for consistency and reliability.

\section{Data analysis}

Data analysis was done hypothesis by hypothesis, testing each one at 0.05 confidence level. Pearson Product Moment Correlation Coefficient Analysis was used to test each of the hypotheses of this study

\section{RESULTS AND DISCUSSION}

Table 1 shows the demographic data of the respondents. Out of 300 respondents, $180(60 \%)$ are male while 120 $(40 \%)$ were female. Also, age group 26-30 (36.00\%) participated more in the survey followed by age group 20$20(31.33 \%)$ and least in age group 5-6 (02.67\%). More married people $188(62.67 \%)$ participated in the survey followed by single $092(30.67 \%)$ and least in widowed 8 (02.67). On the issue of occupation, self-employed 166 $(55.33 \%)$ participated in the survey, followed by student 90 $(30.00 \%)$ and least in civil servants $44(14.67 \%)$. On the level of education, people with tertiary education participate more in the survey 194 (64.67\%), followed by secondary $74(24.67 \%)$ and least in no-formal education 6 $(2.00 \%)$.

\section{Calabar carnival and job creation}

The result of the findings indicates that, there is a positive correlation between Calabar Carnival and job creation in the State. This means that the Calabar Carnival Festival has a significant relationship with employment creation in the state (Figure 1). The result is in agreement with the findings of Compton and Love (2005) who observed that Calabar carnival festival creates employment opportunities and supports local business. The findings also supported Falassi (2009) who maintained that the Calabar Carnival Festival is an industry that is labour-intensive; it has great potential in creating employment opportunities particularly in Cross River State.

The findings of this hypothesis agreed with Huh (2002) who reported that Calabar Carnival Festival create thousands of jobs and tackle the issue of unemployment in the state and Nigeria generally. This is reflected in the fact that the potentials of these events are transformed into source of economic empowerment and employment generation for the people especially women folks and the nation's teeming youths. The festival has generated employment through the investment of small and reputable organisations in various productive activities such as retail, construction, telecommunications and manufacturing.

\section{Calabar carnival and income generation}

The results of hypothesis two revealed that the null hypothesis was rejected in favour of the alternate hypothesis. This means that Calabar Carnival Festival has a significant relationship with income generation in Cross River State. This implies that the state earns much money or income from influx of tourists during the period of the festival (Figure 2). The findings of this hypothesis is in agreement with the National Institute for Culture Orientation (2014) that the Calabar carnival festival has the charity dimension and highlighted activities geared towards generating money for the underprivileged in the state. It is therefore a veritable source of income as the state makes its highest internally generated revenue during festival periods. The findings of this hypothesis strongly supports CRTB (2008) that entrance fees, fees for exhibitors, individual and corporate gifts and market promotional fees, all provide avenue for revenue generation in the state. The finding is also in agreement with Odunsawo (2009) who asserted that globally, carnival contributes significantly to the world economy. He noted that this development has aided the sustainability of economic opportunities for small and medium scale businesses in the creative sector. The findings of this hypothesis agreed with Coffey (2012) who asserted that investing in Calabar Carnival Festival enhances greater income generation opportunities. Calabar carnival festival therefore provides training for the local traders in hospitality, financial management and development of 
Table 1. Respondents' responses on demographic data.

\begin{tabular}{lcc}
\hline Variable & Number & Percentage \\
\hline Sex & 180 & \\
Male & 120 & 60.00 \\
Female & & 40.00 \\
& & \\
Age (Years) & 008 & \\
$5-10$ & 016 & 02.67 \\
$11-15$ & 018 & 05.33 \\
$16-20$ & 094 & 06.00 \\
$21-25$ & 108 & 31.33 \\
$26-30$ & 056 & 36.00 \\
$31-$ Above & & 18.67 \\
& & \\
Marital Status & 092 & \\
Single & 188 & 30.67 \\
Married & 012 & 62.67 \\
Divorced/Separated & 008 & 04.00 \\
Widowed & & 02.67 \\
& & \\
Occupation & 090 & 30.00 \\
Student & 044 & 14.67 \\
Civil Servants & 166 & 55.33 \\
Self-employed & & \\
Education & 026 & 08.67 \\
Primary & 074 & \\
Secondary & 194 & \\
Tertiary & 006 & \\
No formal education & & \\
\hline
\end{tabular}

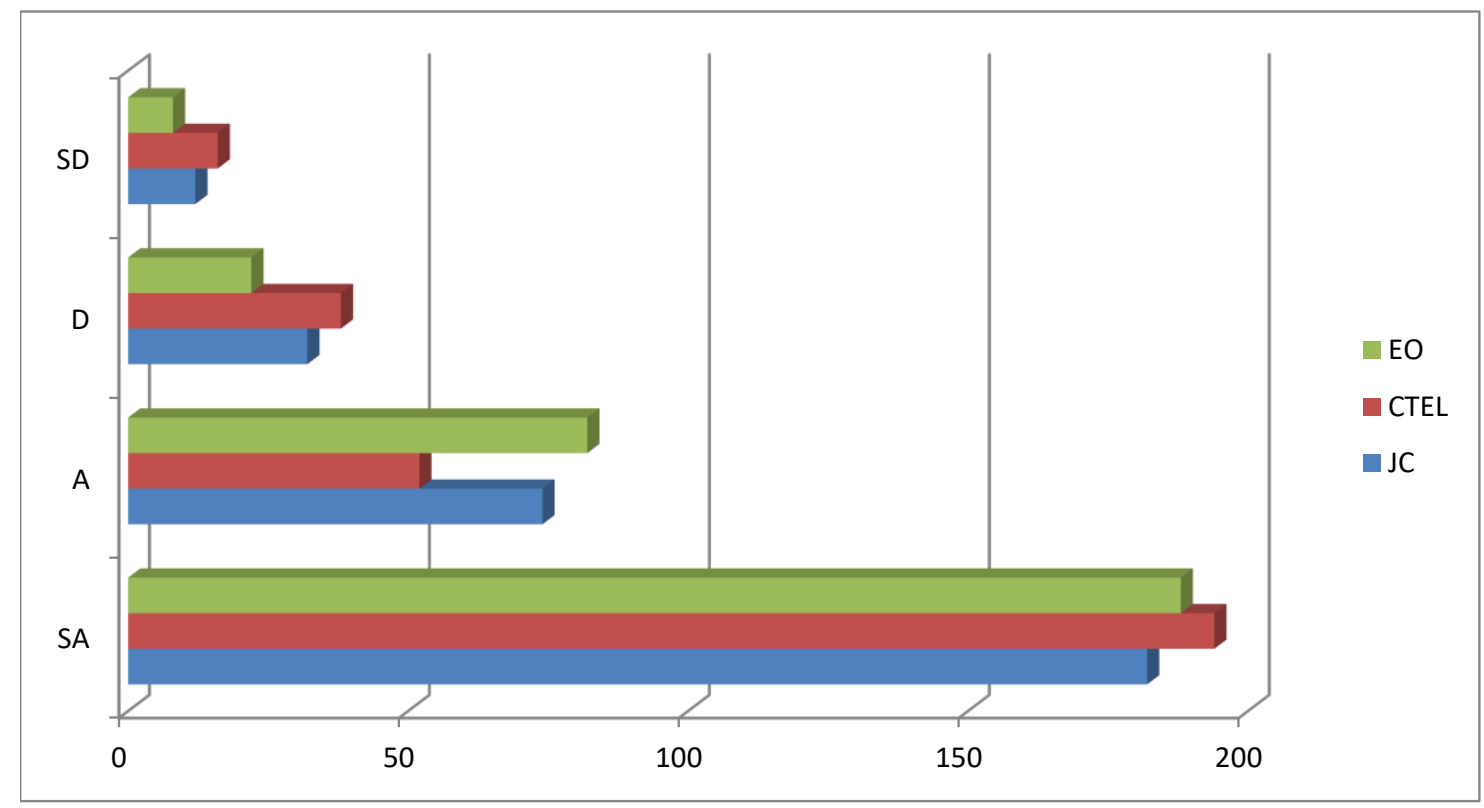

Figure 1. Respondents responses on job creation.

Keys: $\mathrm{EO}=$ Employment Opportunity Creation, $\mathrm{CTEL}=$ Capacity to Enhance Life, $\mathrm{JC}=\mathrm{Job}$ Creation . 


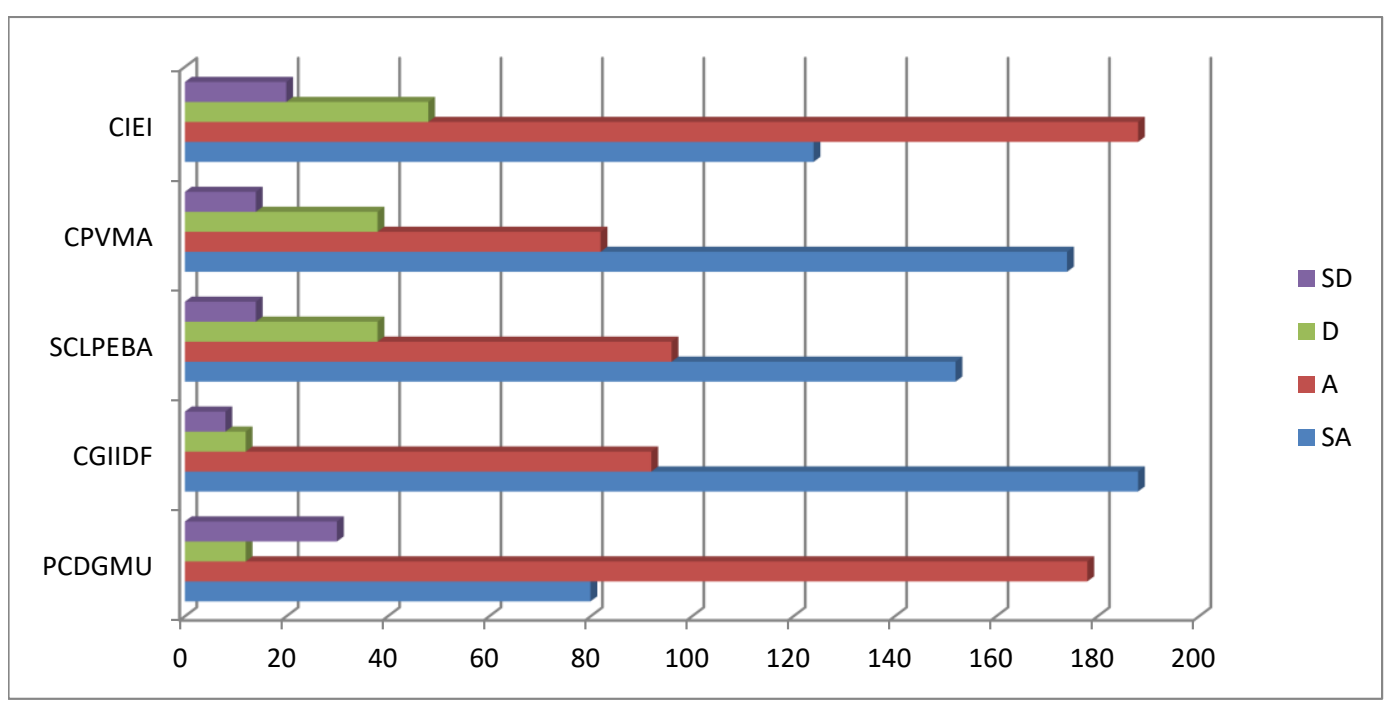

Table 2. Respondents' responses on income generation.

Key: $\mathbf{P C D G M U}=$ Presence of charity dimension and highlighted activities geared towards generating money for the underprivileged in the state, CGIIDF = Ability to generate income from influx of tourists during the period of the festivals, SCLPEBA = Strengthening the capacity of the locals to participate in an economically beneficial way, $\mathbf{C P V M A}=$ Capacity to create platform for brand visibility and market awareness, and $\mathbf{C I E I}=$ Capacity to increase income and exports.

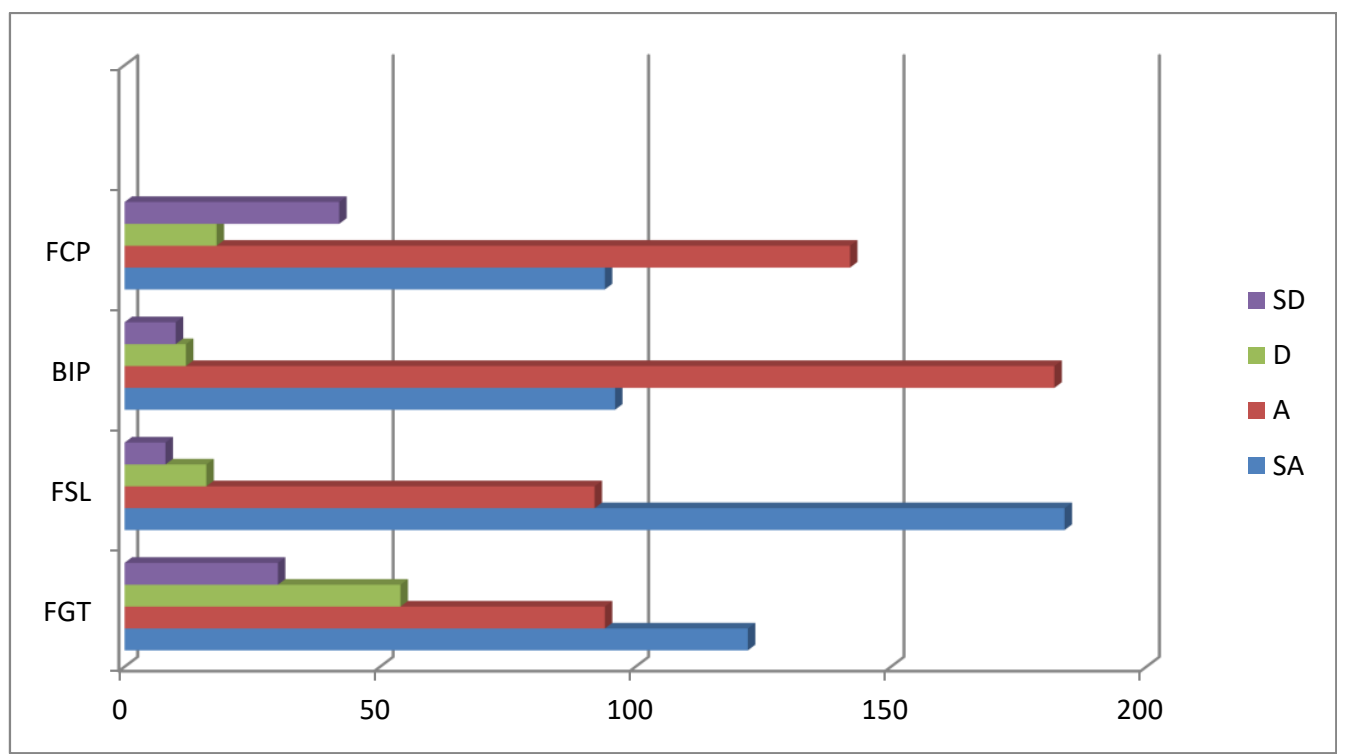

Figure 3. Respondents' responses on infrastructural development.

Key: IIP = Infrastructure improves production capacity, THL = Provision of infrastructure enhances standard of living, ITA = Infrastructure has to do with provision of fixed assets, GTI = Civilized countries attained greatness through infrastructure development, CRI = Country cannot be rich without good infrastructure.

local trade initiatives, to maximise income generated from the increased trading activities.

\section{Calabar carnival and infrastructural development}

The findings indicate that, there is a positive correlation between Calabar carnival and infrastructural development in the state (Figure 3). This signifies that the Calabar carnival festival significantly relate the infrastructural development in Cross River State. Dominic (2011) stated that infrastructural development has in recent times assumed a central importance in Nigeria's fight to attain social and economic stability. This situation brings to the fore the need for Cross River State Government to spend on festivals to drive infrastructural development. The 
provision of the basic social infrastructure like roads, recreational facilities, schools, hospitals, power, water and communication facilities therefore enhances high standard of living which will improve community life as well as promote sustainable development in Cross River State. The findings strongly agreed with Hodge and Greve (2005) that suggested that today Calabar Carnival has helped develop infrastructure system in the State. They reported that a development infrastructure system will in turn improve production capacity of the state and also create positive impact on the overall economic performance.

\section{Conclusion}

As revealed, the Calabar Carnival Festival has the capacity to boost tourism and play a highly significant role in the infrastructural development, job creation and income generation and the overall development of Cross River State by attracting tourism and developing the economy of the state. For this to happen, the social welfare, socioeconomic and security of Nigeria in which Cross River State exists need to be adequately addressed with the public image of the country changed positively or else the talk of making Calabar the tourism hub of the Nation will only be a pipe dream. Furthermore, engaging rural communities during the carnival will be a way to ensure wholesome development of Cross River State since the study is pointing that Calabar Festival drives infrastructural development.

\section{Recommendations}

The study recommends that;

1. The events should incorporate the socio-economic benefits of host communities such as employment creation, income generation and infrastructure development.

2. To promote more private partnership, areas like security must be of paramount importance.

3. For sustainability and viability, the government should establish partnership with visionary leaders comprising of both State, Local Government, nongovernmental agencies and more importantly locals, to be made integral members in tourism business.

4. More effective communication network/publicity of the event should be done to boost the attendance in subsequent carnivals.

5. Emphasis should be placed more on cultural and indigenous content than promoting alien culture.

6. The stakeholders should map out strategies to combat the menace such robberies, prostitutions, pickpocketing etc.

7. The youth can be gainfully employed if competition can be organised between dressmakers which can attract corporate sponsorship and open new careers for the tailor sewing conventional clothes after the carnival.

8. The carnival can be used to hunt for new talents in music and the performing arts with outstanding performance from various Local Government areas across the state, becoming eligible for scholarships and recording contracts abroad.

9. There is also the need for a realistic post impact assessment through commissioned studies. If it must be done, it must be done well.

\section{Suggestions for further studies}

The limitation observed in the course of this study informs the presentation of the following suggestion which is designed to guide future research in similar area of study.

1. Further studies should be embarked upon to validate the results of this research.

2. Similar studies should be carried out in other states that practice this annual event to access the socioeconomic implications of the cultural festival on the people.

3. Further studies should be carried out to identify other socio-economic variables that could influence or promote Calabar carnival festival.

4. The study should also be conducted to cover all the variables that can militate against the cultural festival.

\section{CONFLICT OF INTERESTS}

The authors declare that they have no conflict of interests.

\section{REFERENCES}

Achonwa, R. E. (2007). Tourism and our economy. Mofinews, $7(2), 30-54$

Ajake, A. O. (2006). Sustainable tourism development in Nigeria. Workshop Paper Presentation at Teachers Training Programme on Tourism in Schools, Calabar, June 15.

Allen, J., O'toole, W., McDonnel, I., \& Harris, R. (2002). Festival and Event Management, 2nd edition. New York: John Wiley and Sons.

Bassey-Akamune, F. U., \& Ilomuanya, M. O. (2017). Short term medical mission: Serving the underserved patients in south southern Nigeria. Journal of Public Health and Epidemiology, 9(2), 24-30.

Coffey, G. (2012). Literacy and Technology: Integrating Technology with Small Group, Peer-led Discussions of Literature. International Electronic Journal of Elementary Education, 4(2), 395-405.

Compton, J. L., \& Love, L. L. (2005). The Predictive Validity of Alternative Approaches to evaluating quality of a Festival. Journal of Travel Research, 34(11), 11-24.

CRTB (2008). Pre-event brochure. Calabar: Teamwork.

Dominic, O. (2011) Public private partnership as a tool for infrastructural development in Nigeria. Lagos: Talkback 
Publishing Ltd.

Esekong, A., \& Ibok, E. (2012). Promoting culture and tourism in Nigeria through Calabar Festival and Carnival. Mediterranian Journal of Social Sciences, 3(3), 287-294.

Esu, B. B. (2008). Tourists' satisfaction with cultural tourism festival: A case study of Calabar Carnival Festival Nigeria. International Journal of Business and Management, 4(3), 4-5.

Esu, B. B., Arrey, V. M., Basil, G., \& Eyo, E. E. (2011). Analysis of the economic impacts of cultural festivals: The case of Calabar Carnival in Nigeria. Tourismos: An International Multidisciplinary Journal of Tourism, 6(2), 333-352.

Falassi, A. (2009). Festival: Definition and morphology in Waterman's editor, carnival for elves? The Cultural Politics of Arts Festivals Progress in Human Geography, 54-74.

Falola, T. O., Kirk-Greene, A. H. M., Ajayi, J. F. A., and Udo, R K. (2020). Nigeria. Encyclopedia Britannica. Retrieved 6th November, 2021

from https://www.britannica.com/place/Nigeria.

Felsenstein, D., \& Fleischer, A. (2003). Local festivals and tourism promotion: The role of public assistance and visitor expenditure. Journal of Travel Research, 41(4), 385-392.

Hodge, G. A., \& Greve, C. (Eds.). (2005). The challenge of public-private partnerships: Learning from international experience. Edward Elgar Publishing.

Huh, J. (2002) Tourist satisfaction with cultural/heritage site: The virginia triangle. Unpublished M. Sc, Thesis presented to the Faculty of Virginia polytechnic Institute and State University. Retrieved from http://www.scholar.heb.vt.edu/thesis/available/etd-01540021710/unrestricted/thesis.pdf.

lain, C., Eneida, F., Hannah, M., \& Louise T-W. (2013). Tourism in Africa: Harnessing tourism for growth and improved livelihoods. The World Bank. Retrieved from https://www.worldbank.org/content/dam/Worldbank/doc ument/Africa/Report/africa-tourism-report-2013-

overview.pdf.
Isine, I. (2015). 15 countries to attend Calabar Carnival 2015. Premium Times. Retrieved from https://www.premiumtimesng.com/entertainment/naijafashion/195134-15-countries-to-attend-calabar-carnival2015.html.

National Institute for Culture Orientation (2014). Calabar carnival festival. Retrieved from https://nico.gov.ng/.

Odunsawo, A. (2009). Tourism education passport to sustainable tourism development in Nigeria. Port Harcourt: Garden Bar Publishers.

The World Trade Organization (WTO) (2016). Tourism sector highlighted as important contributor to trade and development. Retrieved from https://www.wto.org/english/news_e/news16_e/bus_13jul16_ e.htm.

Ukwayi, J. K., Ojong, F. E., \& Austine, E. B. (2012). Socioeconomic impact of festivals on community development in Calabar, Nigeria. Developing Country Studies, 2(8), 74-80.

Ulom, F. (2016). History of carnival Calabar, it bands and more. The Paradise. Retrieved 18 October 2019 from https://theparadise.ng/carnival-calabar/.

Wriston Kerlinger, F. N. (1986). Foundation of behavioural research (3rd edition). New York: Holt, Rinehart and Wiston. 